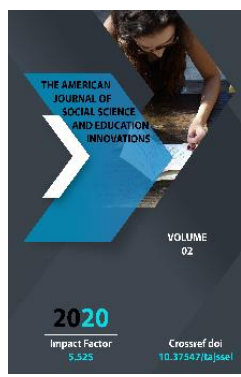

\title{
Developing Linguistic Competence Through Algorithmic Exercises In 5th Grade Mother Tongue Lessons
}

\author{
Turaboeva Muqaddas Yakubjanovna \\ Senior Lecturer Of The Department Of Primary Education, Namangan State University, \\ Uzbekistan
}

Copyright: Original content from this work may be used under the terms of the creative commons attributes 4.0 licence.

\section{ABSTRACT}

This article discusses algorithmic exercises as a means of increasing the effectiveness of 5 th grade mother tongue teaching. In particular, it is scientifically based on the development of pupils' knowledge of linguistic competence through the performance of algorithmic exercises.

\section{KEYWORDS}

Pupil, linguistic competence, practice, mother tongue education, exercises, algorithmic exercises, logical thinking, conscious comprehension, thinking, activity, interpretation of words, sentence construction.

\section{INTRODUCTION}

Today, the purpose of public education is to organize the general secondary education system based on the best practices of developed countries and science and modern information and communication technologies and the ongoing socio-economic reforms in our country focused on educating of spiritually mature and intellectually developed person.
As part of the reform of the education system in the renewed Uzbekistan, the important tasks were identified in the Concept of Development of the Public Education System until 2030 includes "Improvement of teaching methods, gradual implementation of the principles of individualization in the educational process, the formation of healthy, strong and effective motivation for early 
childhood education" [1]. This concept requires a radical reform of general secondary education, including primary education, the development of pupils' oral and written literacy on the basis of international educational standards with special emphasis on the quality and effectiveness of mother tongue education. As the President Shavkat Mirziyoyev emphasized "Each of us must consider the attention to the state language as attention to independence, respect and devotion to the state language as respect and devotion to the motherland and make such a view a rule of our lives. We must start this noble movement from ourselves, our families and communities, show respect for our native language, traditions and values, and show our love for the Motherland in practice. "[2] In order to fulfill such a high and important social task, it is essential to create a system of algorithmic exercises based on certain rules and regulations, focusing on the acquisition of mother tongue education, in particular, the acquisition of scientific and theoretical knowledge and practical skills in language and speech improvement as well.

\section{MATERIALS AND METHODS}

The main goal of teaching mother tongue is to develop a person who can express himself / herself correctly and fluently in oral and written form and who has a culture of reading, who can think independently and creatively, who understands the opinions of others - a culture of communication and speech. Exercise in mother tongue education has a special scientific and methodological significance. Exercise is a learning task related to the performance of knowledge, methods of activity in the same learning environment in the context of this or that topic. Knowledge is recalled during the exercise; knowledge, method of activity is applied to the learning mode; the activity of the subject (person) is improved. For this reason, the textbooks provide several exercises on each topic, and special attention is paid to the performance of exercises during the lesson. In our views, the use of algorithmic exercises in mother tongue education gives good scientific and methodological results.

The term "algorithm" is defined in the "Explanatory Dictionary of the Uzbek language". Algorithm [lat. the word "algorithm" is actually derived from the name of the great Uzbek mathematician AlKhwarizmi, who lived in the $X$ century, and means "a clear rule (program) about the performance of actions in a certain order, used to solve problems of a certain type" [3].

The word algorithm is used based on the specific characteristics of each science. In particular, the term algorithmic exercise is used in mother tongue teaching as well, based on the lexical meaning of the words algorithm and exercise. In our view, the term algorithmic exercise can be defined in terms of mother tonguescience. Algorithmic exercises are based on the principle of moving from practice to theory to strengthen and enrich pupils' knowledge, skills and abilities in language and speech in several topics and to develop consistent, free, independent, creative, logical thinking and observation, focused, multi-step, sequential exercises based on specific procedures.

One of the peculiarities of algorithmic learning is that the learning material is divided into different algorithms. Algorithmic exercises are also an example of algorithmic learning. 
The pupil actively participates in algorithmic learning. In this case, the teacher and pupil activities are carried out as follows:

1. The teacher makes the exercises in different algorithms.

2. Algorithms are given to pupils as a problem.

3. Exercise assignments cover not only the topic being studied, but also previously studied topics consisted of several steps based on a sequence.

4. Pupils are offered to express their views on the given tasks and the ways to solve the problem.

5. The teacher asks the pupils to find the right solution to a particular problem.

6. Pupils try to draw independent conclusions based on their knowledge, skills and abilities.

7. Exercises encourage pupils to think creatively and logically, and develop such activities.

8. The teacher discusses the conclusion with the children.

9. The teacher completes, explains and enriches the conclusion.

10. The teacher suggests the application of theoretical knowledge to various practical situations.

Based on the above steps, a series of activities will be organized. This activity takes the form of algorithmic learning.

The psychological basis of learning tasks for pupils' memory is the phenomenon of memory - the recall of learned knowledge, its application to the learning situation, the further definition of methods of knowledge and activity. Pupils' memory also works in the performance of exercises that constitute the main type of educational activity in mother tongue education.

The main tasks of teaching the mother tongue:

To develop the pupil's speaking competence, which is aimed at thinking about the person, understanding the opinion of others, expressing their opinion orally and in writing;

$>$ To develop pupils' knowledge of grammar (phonetics, lexicology, word structure, word formation, morphology, syntax, writing and spelling, punctuation, speech styles, stylistics);

The formation of linguistic competencies aimed at developing the ability to express accurately and fluently using the vast potential of the native language.

For example: Let's do the exercise given in the 5th grade mother tonguetextbook algorithmically.

Exercise 30 1. Read the following words correctly.

2. Notice the difference in meaning and make sentences with them.

Yondash - yondosh (adjacent-close), uyim uyum (my house - heap, pile) tasir - ta'sir (impact - influence), mard - mart (courage March), qiymat - qimmat (value - expensive), kaft-kift (palm-shoulder).

1. Explain the meaning of each word.

Adjacent - to come side by side, to approach; close - near to, next to, side by side; My house -the owner of a residential building; heap/pile/packed- something piled on the ground; Impact - means a repetitive sound; influence - the urge to do something through action or word. Brave - who does not know 
fear; fearless, brave, courageous; March is the third month of the new year. Value - the price of the goods; expensive - wealth is an expensive valuation thing; cost, appraisal; Palm - the entire integral part of the inner and lower part of the foot from the wrist to the fingers; the part of the body from the neck to the arms; shoulder -the part of the garment that stands on the shoulder, covering the shoulder;

2. Make sentences using words which explained the meanings.

Yondash xonada dars o'tilmoqda (The lesson are being held in the adjoining room). Oshxonada idish-tovoqlar yondosh turibdi (The dishes are next to each other in the kitchen). Vatanim-uyim (My country is my homeland). Oziq-ovqatlar qishga uyum qilib quyilgan (The food is packed for the winter). Iqtidorli o'quvchilar past o'zlashtiruvchi o'quvchilarga ta'sir o'tkazdi (Gifted pupils were affected by low-achieving pupils). Mart oyida bayramlar ko'p (There are many holidays in March). Binokorlik ishlarining qiymati ancha ko'tarildi (The cost of construction work has raised significantly). Sovg'a qimmat ekan (The gift is expensive). Ona kaftini ochib duo qildi (The mother opened her hands and prayed). Chevar kiftni o'lchadi (dressmakes measured the size of shoulder).

In this way, the lesson focuses on the unity of language units - sounds (phonemes), letters and words, adheres to the principle of continuity in teaching, pupils' knowledge of phonetics, graphics and lexicology, i.e the correct use of sounds (phonemes) and letters, interpretation of words, skills and abilities are strengthened and developed.

It is said that sounds (phonemes), letters play an important role in the formation and expression of the word, their change, improper use can change the meaning of the word; some knowledge of word structure (morphemes) is also given. As a result of the use of algorithmic exercises in mother tongue education, pupils' abilities, aspirations and interests are given priority, independent and creative thinking, fluency in oral and written speech are formed.

\section{CONCLUSION}

As algorithmic exercises require creativity and might cause some difficulty in the learning process, as logical thinking can be confusing for pupils. Therefore, when working on algorithmic exercises, the skills of the teacher and the mental characteristics of pupils should be taken into account. This requires the real learning opportunities of each pupil.

\section{REFERENCES}

1. Decree of the President of the Republic of Uzbekistan №-5712 "On approval of the Concept of development of the public education system of the Republic of Uzbekistan until 2030" on April 29, 2019

2. Speech by President Shavkat Mirziyoyev at the ceremony dedicated to the thirtieth anniversary of the status of the Uzbek language as the state language // https://uza.uz/en/politics/president-

shavkat-mirziyeev-uzbek-tiliga-davlat-tilima-o-21-10-2019.

3. Annotated dictionary of the Uzbek language. - Tashkent: National Encyclopedia of Uzbekistan, 2000. p.680.

4. N.Mahmudov, A.Sobirov, Sh.Sattarov, Sh.Toshmirzaeva, D.Mannopova. 5th grade mother tongue textbook. Tashkent. 2020.

5. On approval of state educational standards of general secondary and secondary special, vocational education (Collection of 
Legislation of the Republic of Uzbekistan, 2017, No. 14, Article 230).

6. Turaboeva, M. (2019). ALGORITHMIC EXERCISES AND THEIR SPECIAL FEATURES. Scientific Bulletin of Namangan State University, 1(2), 284-289.

7. Turaboyeva, M. Y. (2019). THE IMPORTANCE OF IMPLEMENTING ALGORITHMIC EXERCISES IN TEACHING SYNTAX ELEMENTS IN PRIMARY CLASS MOTHER TONGUE LESSONS. European Journal of Research and Reflection in Educational Sciences Vol, 7(12).

8. Turaboyeva, M. Y. (2019). EFFICIENCY OF APPLYING ALGORYTHMIC EXERCISES IN TEACHING MOTHER TONGUE. Scientific Bulletin of Namangan State University, 1(10), 345-352. 